\title{
Parental Smoking and Smoking Cognitions among Youth: A Systematic Review of the Literature
}

\author{
Kirsten Lochbuehler ${ }^{a, c}$ Kathrin Schuck ${ }^{b, c}$ Roy Otten ${ }^{c, d}$ Linda Ringlever ${ }^{c}$ \\ Marieke Hiemstra ${ }^{c, e}$
}

${ }^{a}$ Annenberg School for Communication, University of Pennsylvania, Philadelphia, Pa., USA; b Faculty of Psychology, Mental Health Research and Treatment Center, University of Bochum, Bochum, Germany; ' ${ }^{`}$ Behavioural Science Institute, Radboud University Nijmegen, ${ }^{\mathrm{d}}$ Research and Development, Pluryn, Nijmegen, and e Research Centre for Adolescent Development, University Utrecht, Utrecht, The Netherlands

\section{Key Words}

Parental smoking · Adolescents · Youth · Children · Explicit cognitions $\cdot$ Implicit cognitions

\begin{abstract}
Aims: We summarized and discussed the empirical evidence for an association between parental smoking and smokingrelated cognitions among youth and for the mediating role of smoking-related cognitions in the relation between parental and youth smoking behaviour. Methods: We conducted a systematic review of articles published between 1980 and February 2015 using the databases Psychlnfo and PubMed. Results: The systematic search resulted in 41 eligible studies. Only 4 studies investigated smoking-related cognitions as putative mediators in the association between parental and youth smoking. The synthesis of evidence showed a mix of significant and non-significant associations between parental smoking and smoking-related cognitions among youth. A majority of results reported positive associations even when non-significant findings were found. However, studies that report an effect suggest that the effect may be quite modest. Conclusion: Empirical evidence does not confirm the commonly applied assertions of social learn-
\end{abstract}

\section{KARGER}

E-Mail karger@karger.com

www.karger.com/ear ing theories that parental smoking increases the risk of youth smoking through the development of favourable smokingrelated cognitions. Methodological and theoretical aspects that might explain the lack of consistent findings are discussed.

(c) 2016 S. Karger AG, Basel

\section{Introduction}

A large body of research has provided evidence for the link between parental smoking and smoking in adolescents [1-3]. A recent meta-analysis concluded that the risk of smoking uptake is nearly threefold if both parents smoke [1], and numerous studies show that parental smoking and exposure to second-hand smoke constitute risk factors for higher rates of smoking and progression into nicotine dependence among youth [4-7]. Up to this point, however, it is yet unclear how parental smoking contributes to smoking in adolescents. Adolescents' smoking-related cognitions have been proposed to underlie the intergenerational transmission of smoking behaviour. Cognitive models have described 2 somewhat overlapping pathways, which may help to further under-
(C) 2016 S. Karger AG, Basel

$1022-6877 / 16 / 0224-0215 \$ 39.50 / 0$ 
stand the mechanisms underlying the association between parental and youth smoking.

One line of research describes an explicit pathway of transmission, which involves conscious elaboration and explicit decision-making processes. Theories of health behaviour and social learning theories, such as the Theory of Planned Behaviour (TPB) [8] and the Social Cognitive Theory (SCT) [9] assume that the decision to engage in substance use is based on the rational evaluation of the positive and negative consequences of substance use. According to these theories, explicit cognitions (e.g. expectancies, normative perceptions, attitudes) are important predictors of the decision to engage in certain behaviours. For example, the TPB [8] postulates that behaviour is determined by behavioural intention which, in turn, depend on personal attitudes towards the behaviour, subjective norms, and perceived behavioural control over the behaviour (self-efficacy). In addition, explicit cognitions are hypothesized to mediate the influence of others on individual behaviour. For example, the SCT [9] posits that the observation of a certain behaviour by significant others shapes cognitions and leads to the adoption and imitation of this behaviour.

Recent literature describes a second possible pathway that also considers the role of implicit smoking-related cognitions [10-14]. Implicit transmission involves the formation of cognitive processes that are more automatic and less readily accessible by introspection or self-report (e.g. attentional processes, memory associations, information processing). Models and theories that consider implicit cognitions, such as dual process models (e.g. [14]), extend the assumption that the decision to engage in a certain behaviour is solely based on a rational process and hypothesize that substance use may also be affected by relatively automatic or impulsive processes that are formed and activated by environmental cues. While explicit (conscious, reflective, controlled) cognitive processes involve deliberate and conscious appraisals of available information, implicit (automatic, impulsive) processes refer to automatic associations that do not depend on deliberate or conscious recollection.

Both explicit and implicit cognitive processes are assumed to be influenced by the social environment. Parents are one of the most important sources that influence cognitions and behaviour of youth. The intergenerational transmission of smoking behaviour has been well established (for a review see [1]). The purpose of the current review is to summarize and discuss the empirical evidence for (1) an association between parental smoking and smoking-related cognitions among youth as well as the empirical evidence for (2) the mediating role of smoking-related cognitions in the relation between parental and youth smoking. We did not conduct a formal metaanalysis due to the variation of cognitive outcome measures used in different studies, which did not allow for statistical comparisons to be performed between studies. The main aim of this review was to summarize and discuss the current state of the literature in this field and to suggest implications for theory and future research.

\section{Methods}

\section{Data Sources}

We conducted comprehensive searches of the databases PsychInfo and PubMed for studies assessing the association between parental smoking and youth smoking-related cognitions published between 1980 and February 2015. To be included, a study had to measure parental smoking as an independent variable and smoking-related cognitions in children/adolescents as an outcome variable/mediator. Measures of parental smoking included having at least one currently smoking parent, having at least one ever smoking parent, the number of currently smoking parents, and the frequency of parental smoking. Measures of explicit smoking-related cognitions in youth included smoking-related attitudes, beliefs, perceptions, expectancies, norms, prototypes, the inclination to smoke (i.e. willingness, susceptibility, motivation), and the intention to smoke. Due to a limited number of studies, the search on implicit cognitions was extended to smoking and implicit cognitions (i.e. automatic smoking-related memory associations, selective attention and automatic approach tendencies). The search terms are listed in the supplementary material (see www.karger.com/doi/10.1159/000446022). Other inclusion criteria were full-text availability, report published as a journal article, present original data, and the report had to be published in English. In cases in which multiple studies used the same dataset, we included the study with the greatest methodological quality as assessed by the Newcastle-Ottawa Scale (NOS) [15]. In cases in which analyses were conducted for different reporters, we reported the results based on child-report. If full-text articles were unavailable, attempts to obtain full-text articles from the authors were made. In addition, we hand-searched the reference lists from identified relevant articles. A systematic review was carried out in accordance with the PRISMA statement [16].

\section{Data Extraction and Quality Assessment}

All authors participated in the assessment of eligibility of abstracts and full-texts and the data-extraction process. First, titles and abstracts identified from database searches were assessed for eligibility, excluding irrelevant ones. Then, full-texts of papers were assessed for eligibility. Papers were sorted in a way that each paper was independently assessed by at least 2 authors. Disagreements were resolved through discussion with the other authors. Also, data extraction was conducted independently by at least 2 authors and by using a data extraction form. The NOS [15] was used to assess the quality of the included studies based on selection of subjects, comparability of subjects, and assessment of outcome. 
Fig. 1. Flowchart of included studies for explicit cognitions.

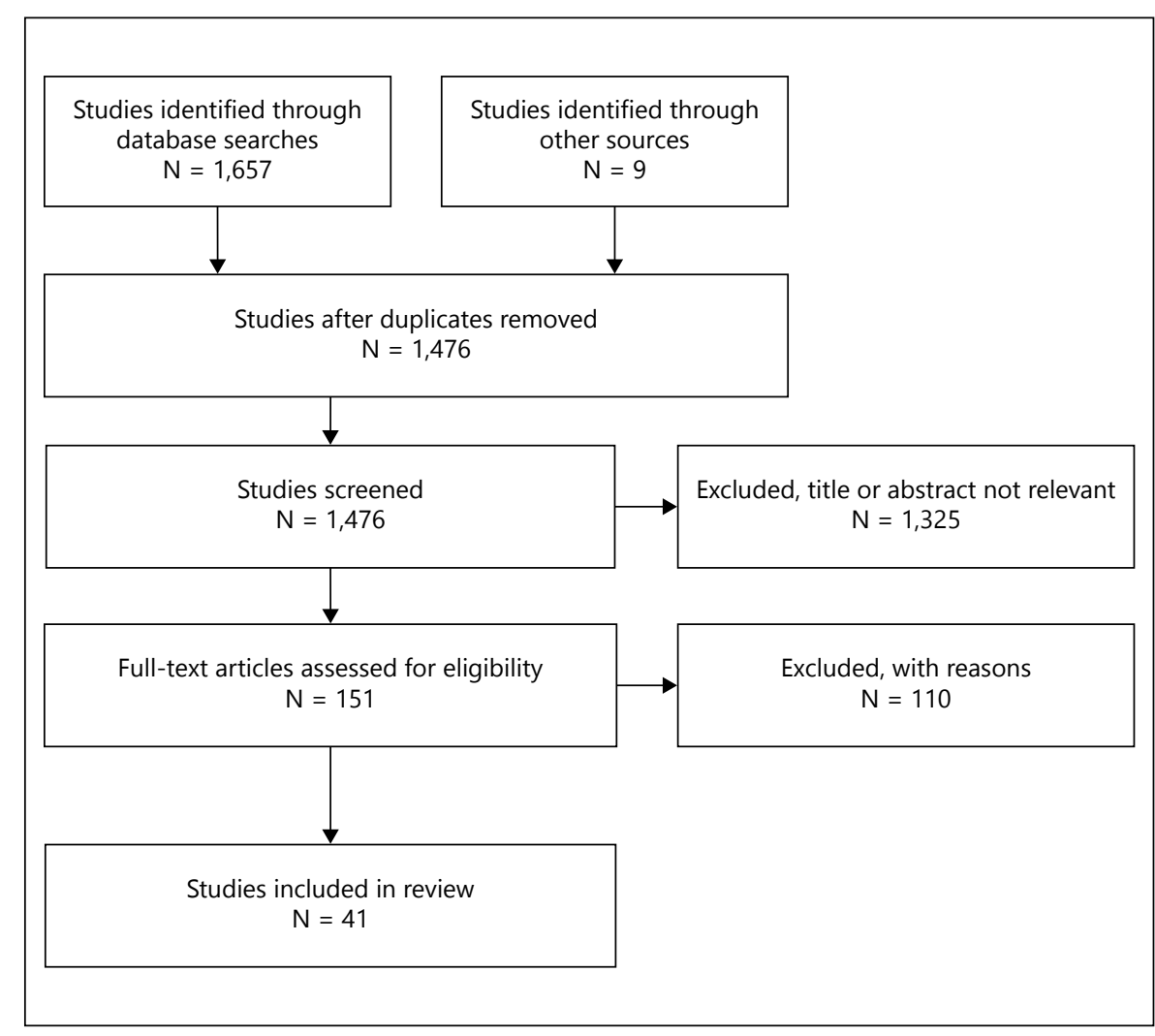

\section{Results}

\section{Overview of Included Studies}

Regarding explicit cognitions, the initial search identified 1,657 non-duplicated, potentially eligible studies. After reviewing the titles and abstracts, we retained 151 fulltext articles for detailed evaluation. Review of their reference lists yielded 3 additional studies and 6 extra studies were identified by the authors. After examination of the full-text articles, 110 studies were excluded because parental smoking or smoking-related cognitions were not measured, relevant data were not provided, the study was not published in English, or the same dataset was used in another article, which yielded a higher quality. With regard to implicit cognitions, the initial search and the review of titles and abstracts resulted in 13 full-text articles that were reviewed for detailed evaluation. Of those, 3 studies fulfilled the criteria for inclusion. These 3 studies assessed both implicit and explicit cognitions and were also identified in the search for explicit cognitions. In total, 41 studies were included in this systematic review (see flowcharts, fig. 1 and 2).

A majority of studies were conducted in the United States or Europe and reviewed non-systematically ascer- tained school-samples. Most studies measured parental smoking based on child reports. Of the 41 studies, 30 were cross-sectional. Eight studies used a longitudinal design to examine the association between parental smoking and smoking-related cognitions in youth. Four studies aimed at evaluating adolescent's cognitions as potential mediators in the association between parental and adolescent smoking. A majority of studies reported the effects of parental smoking on multiple smoking-related cognitions in adolescents. The age range of children was mainly between 9 and 18 years. Exceptions were 2 studies, in which older samples (14-24/13-21 years) were used $[17,18]$ and a study focusing on a younger sample (mean age 6.9) [19]. The quality of the studies ranged from 1 to 6 on the 9-point NOS [15], with a median score of 3.5. In the following sections, we present findings separately for cross-sectional, longitudinal, and mediation studies to distinguish between the methodological quality of studies and the quality of the evidence.

\section{Cross-Sectional Studies}

In this section, we focus on the results of constructs posited by the TPB [8], the SCT [20] and by dual process models: global attitudes towards smoking, normative be- 
Fig. 2. Flow chart of included studies for implicit cognitions.

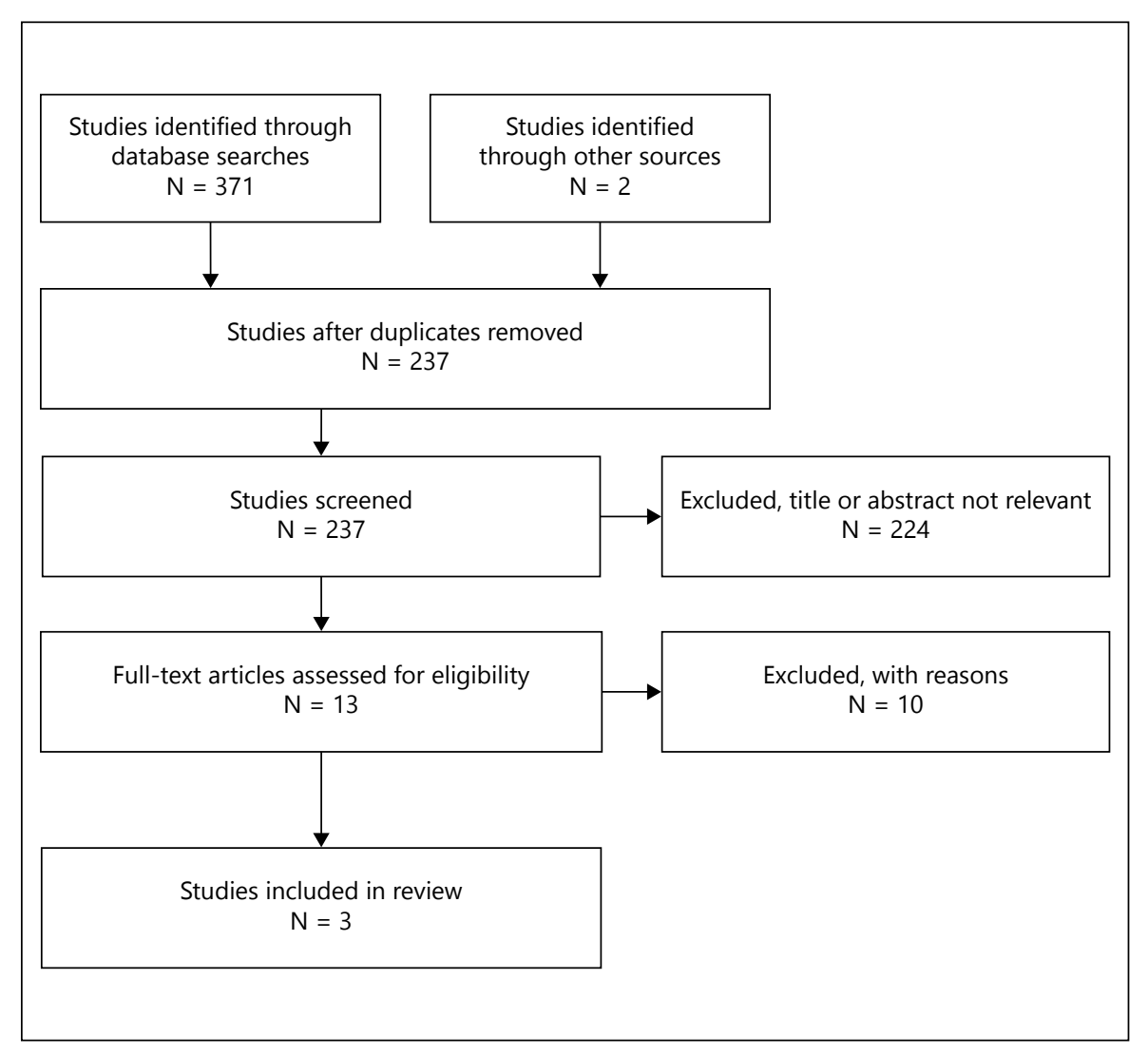

liefs, self-efficacy, smoking-related expectancies, intentions to smoke, and implicit smoking-related cognitions. Additionally, we present the results regarding susceptibility to smoking [21]. The results of all studies can be found in tables 1 and 2.

Of the 30 studies that employed a cross-sectional design to assess the association between parental smoking and adolescent's smoking-related cognitions, the 5 studies that investigated the association between parental smoking and global attitudes towards smoking showed inconsistent findings. One study reported evidence for a positive association between parental smoking and positive attitudes towards smoking [22], whereas 4 studies found no significant association [23-26].

With regard to injunctive norms, 3 studies found parental smoking to be associated with adolescent's perceived approval of smoking from their parents [27, 28] and with mothers' and friends' approval of smoking [22]. Three studies investigated the association between parental smoking and adolescent's descriptive norms (perception of adult and/or peer smoking prevalence). Two studies found evidence for an association between parental smoking and higher perceived adult smoking prevalence
$[29,30]$, whereas one study did not find this association [26]. Furthermore, 2 studies reported that adolescents with smoking parents overestimated the smoking prevalence of their peers compared with adolescents with nonsmoking parents $[26,30]$.

In total, 3 studies investigated the association between parental smoking and self-efficacy. Two studies assessing the self-efficacy to resist smoking in samples of adolescent smokers found that adolescent smokers with smoking parents reported lower self-efficacy to resist smoking than adolescent smokers with non-smoking parents $[31,32]$. In one other study, parental smoking was not associated with higher self-efficacy to refuse tobacco in a sample that tested smoking as well as non-smoking adolescents [22].

Two studies found that parental smoking increased general positive smoking-related expectancies [33, 34], while one study did not find this association [31]. A majority of studies showed no association between parental smoking and personal negative smoking-related expectancies [24] or personal positive smoking-related expectancies $[29,32]$. Only one study found parental smoking to be positively related to positive personal smoking-related expectancies [24]. 


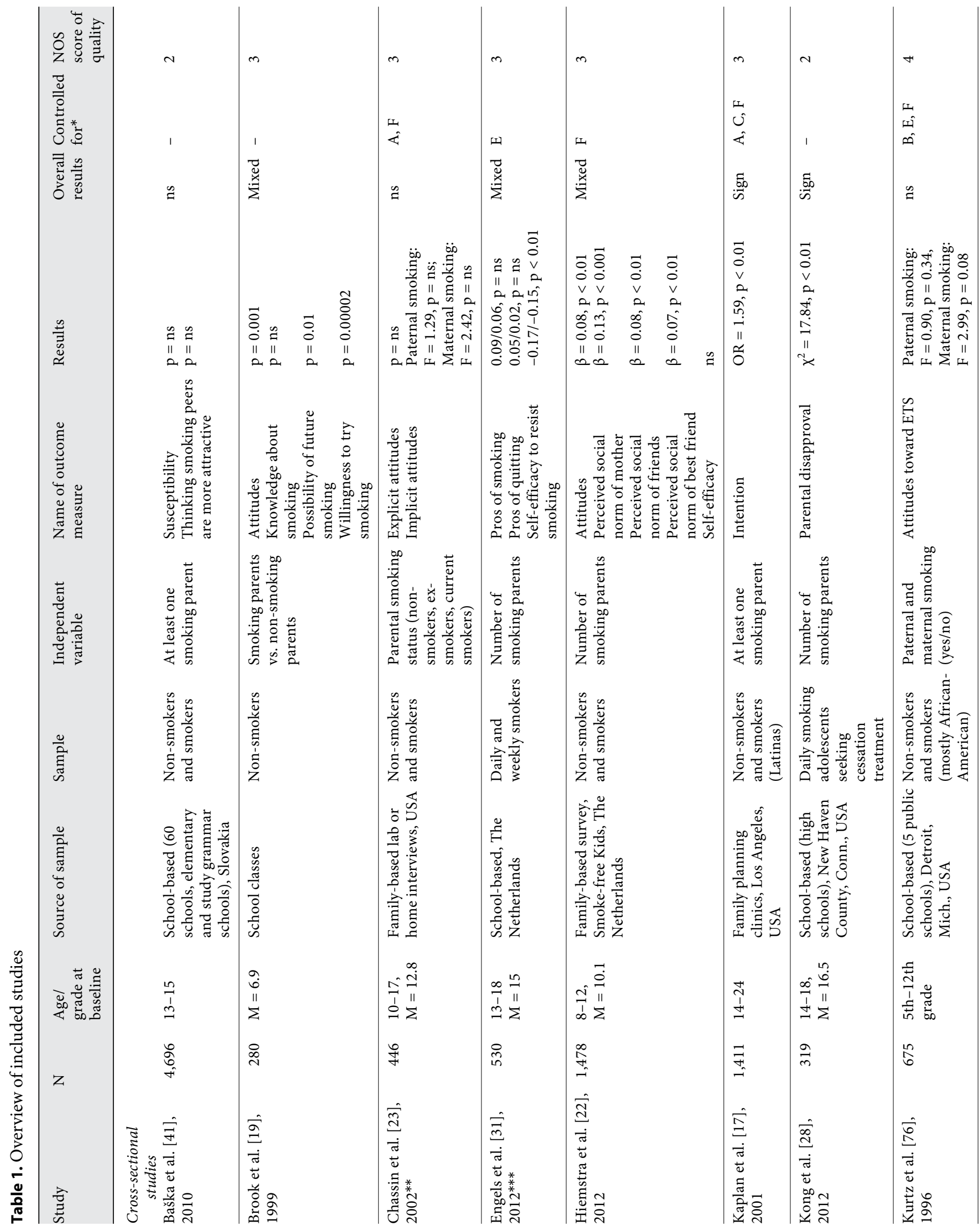




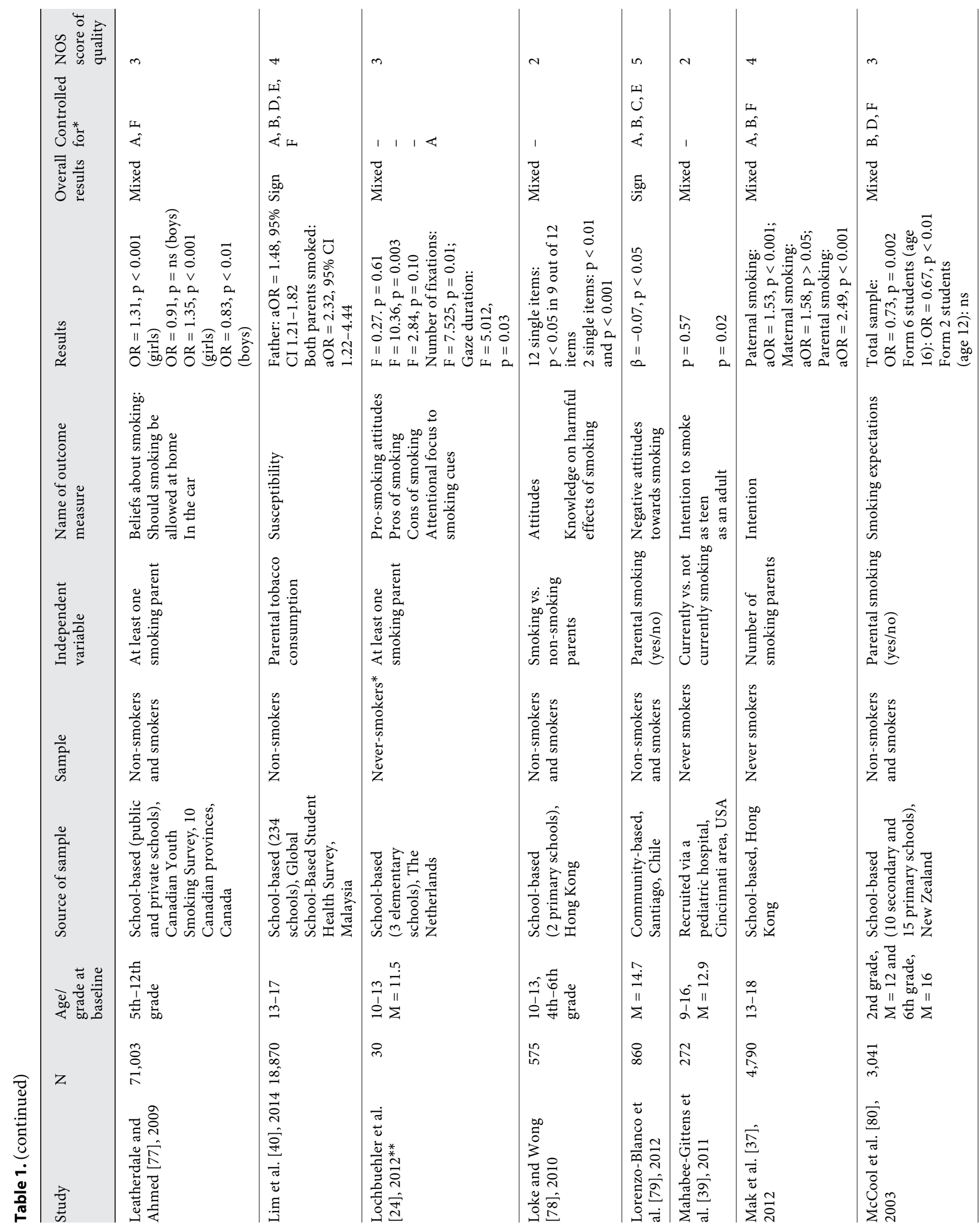




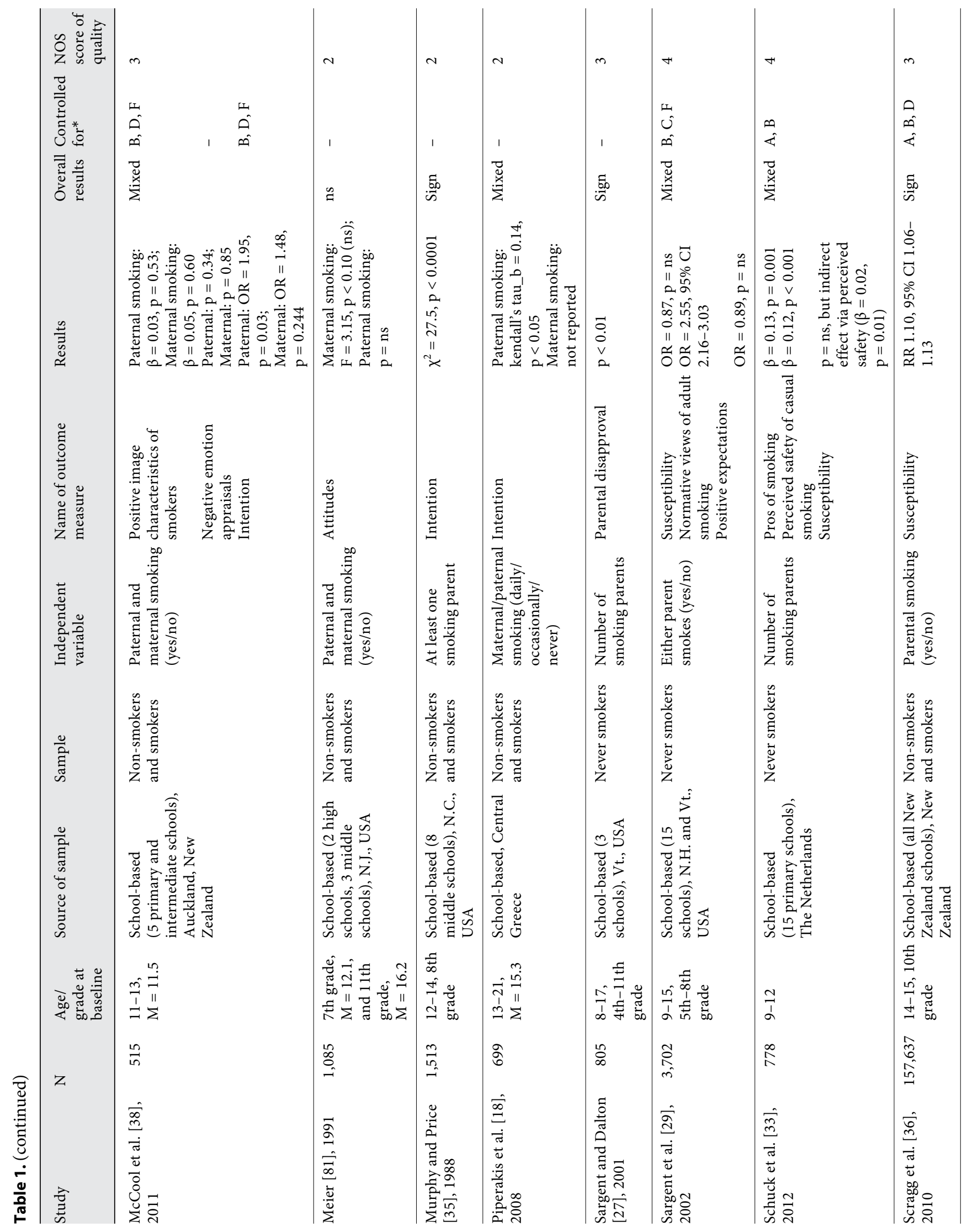




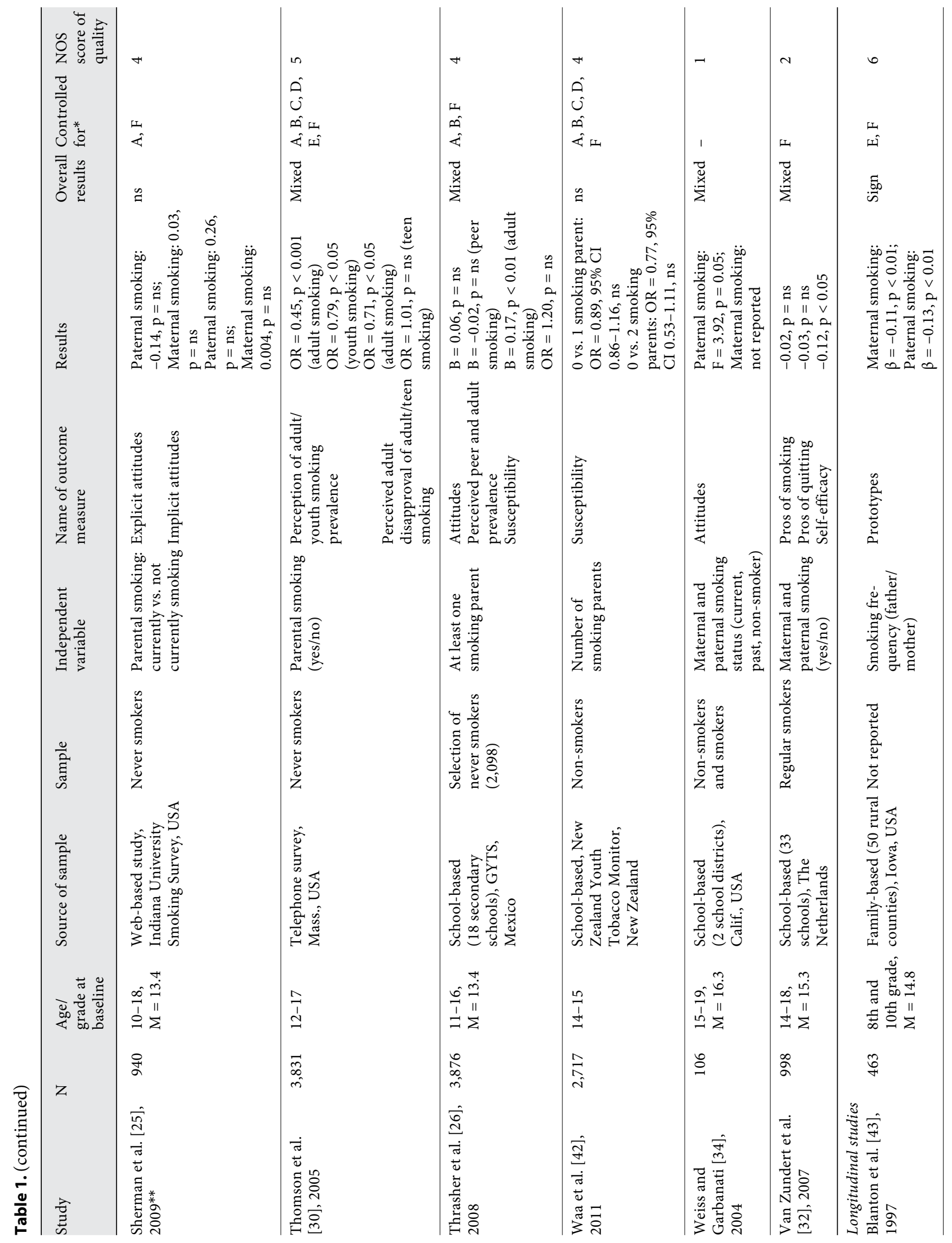




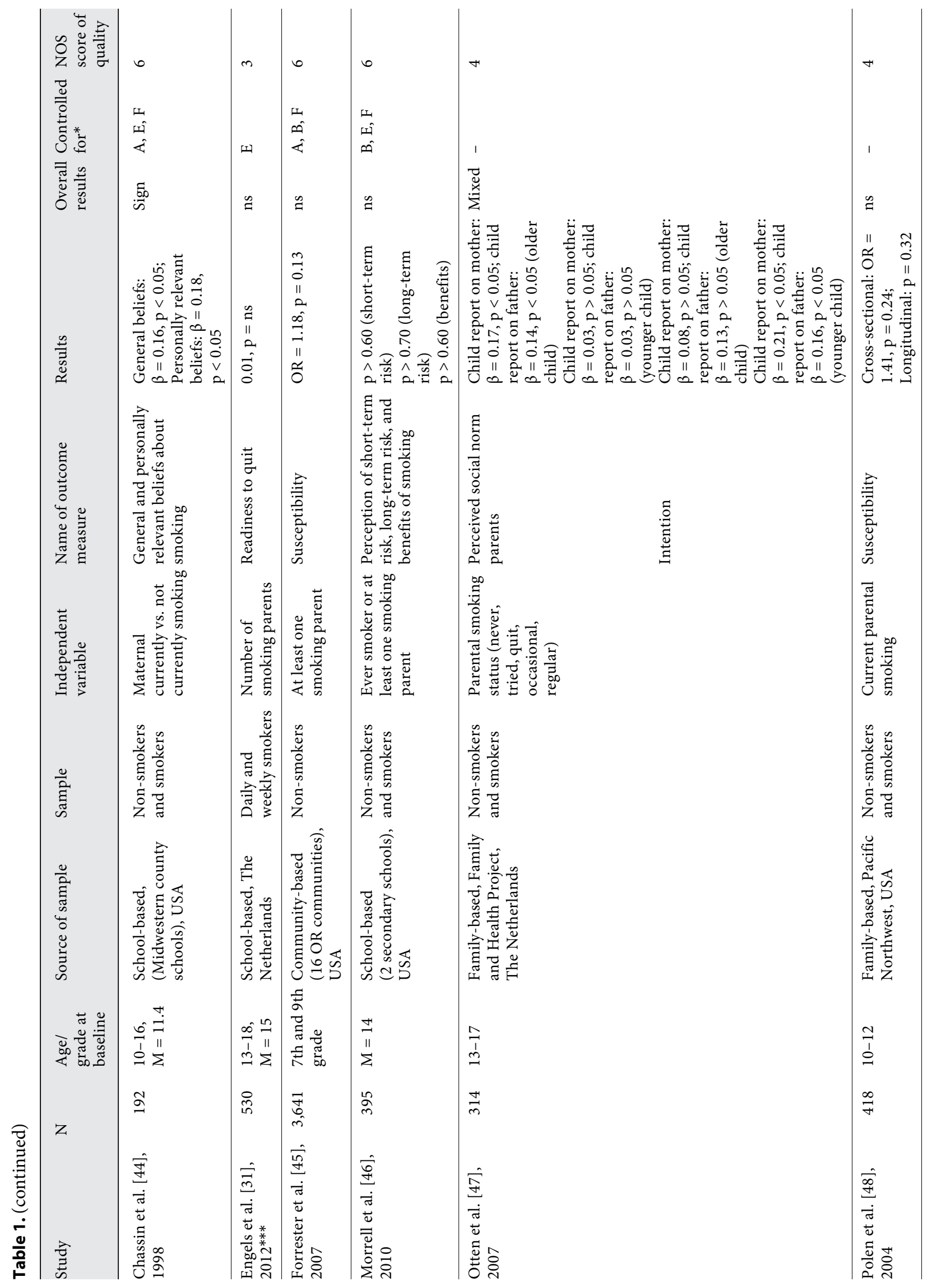




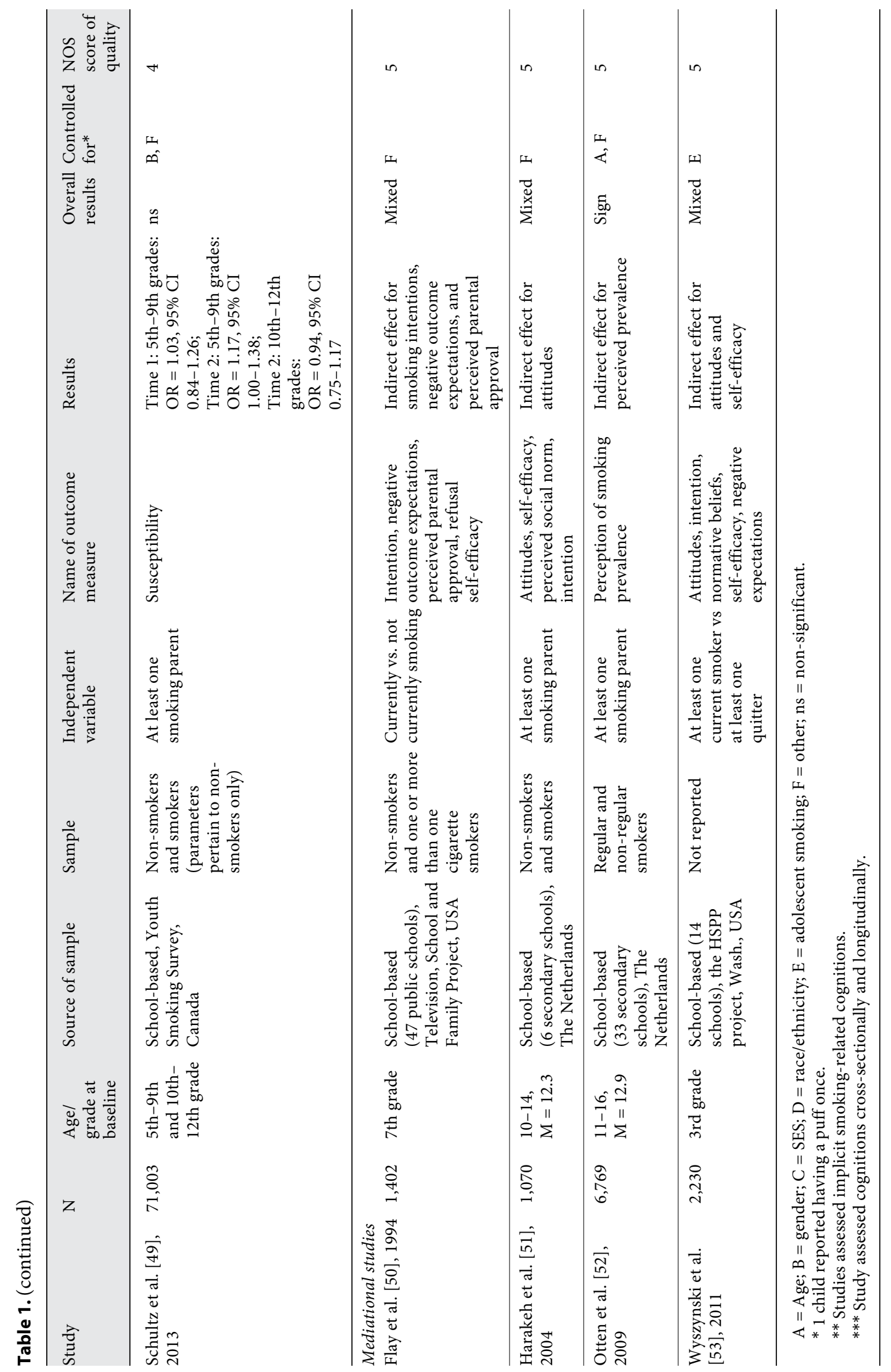




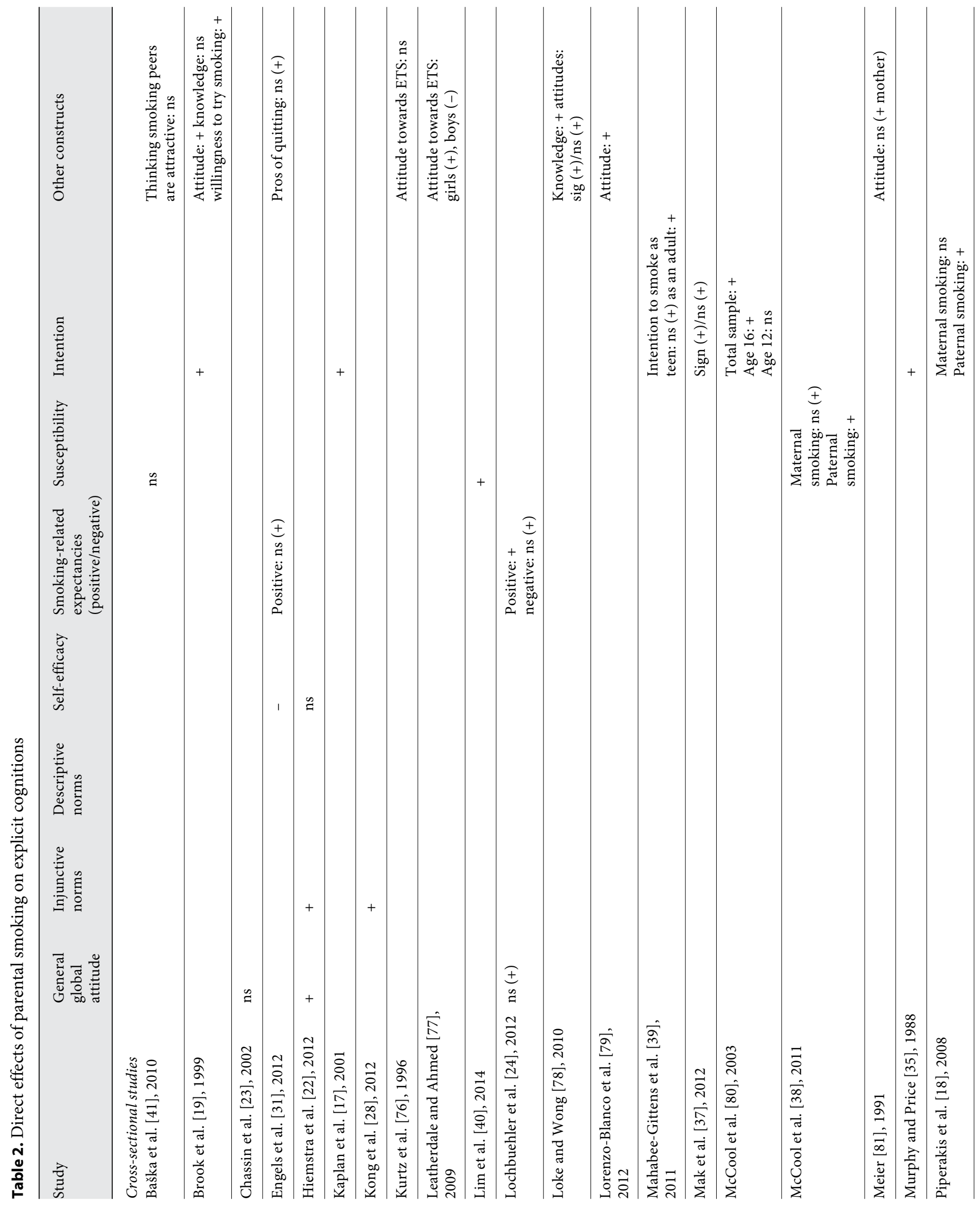




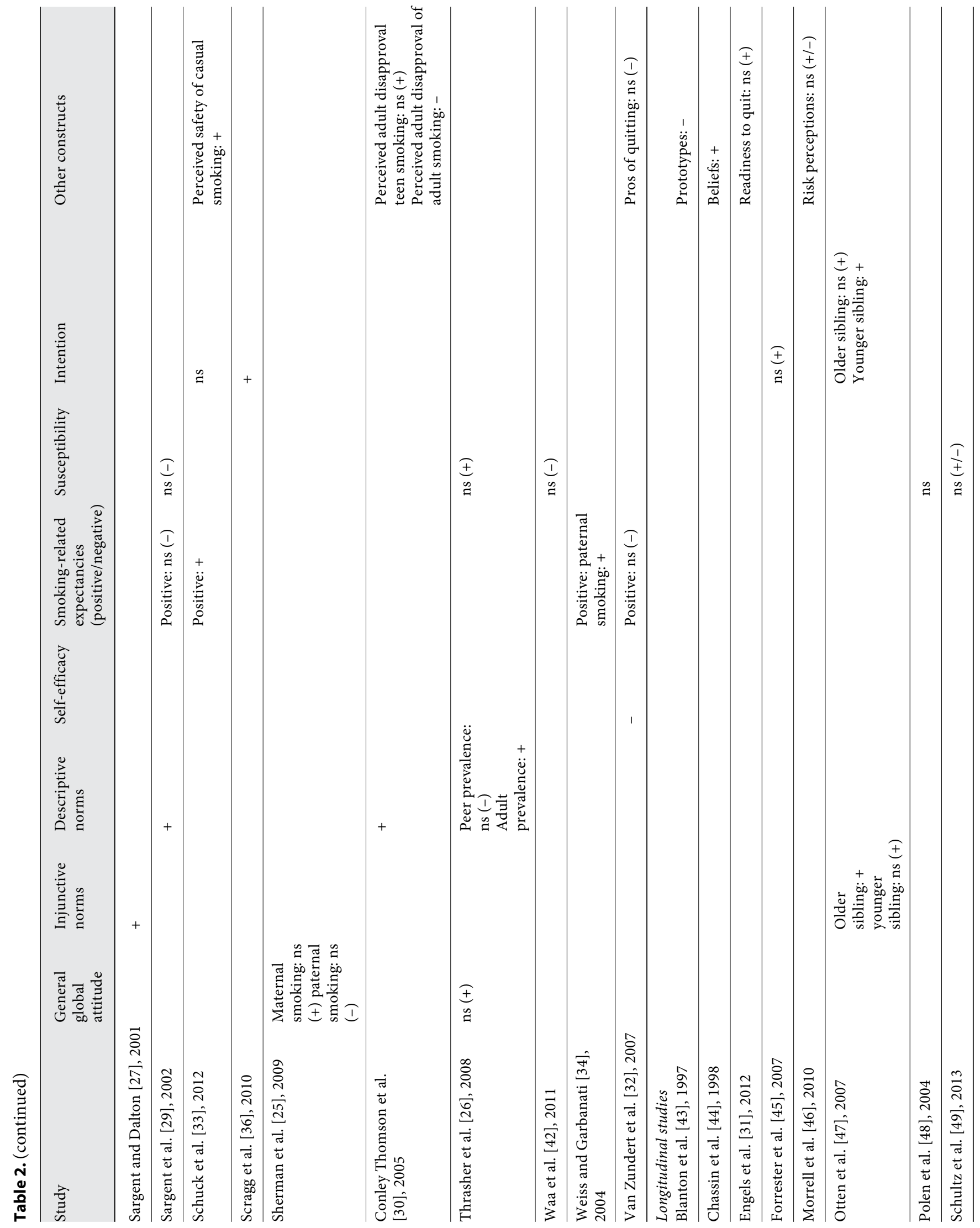




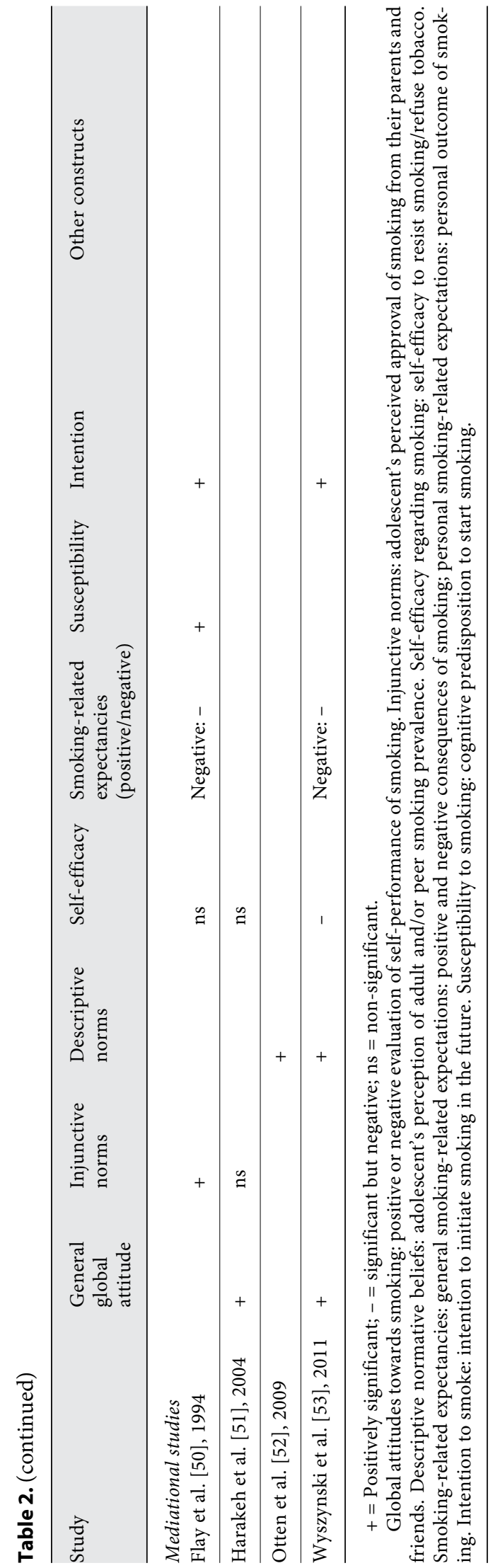

Parental Smoking and Youth Smoking Cognitions
Of the 9 studies that investigated the association between parental smoking and intentions to smoke, 5 studies reported significant associations $[17,19,35-$ 37], while non-significant associations were found in one study [33]. When analyses were conducted separately for paternal and maternal smoking, only fathers seemed to affect adolescent's intentions to smoke [18, 37, 38]. Mahabee-Gittens et al. [39] found that parental smoking was positively related to the intention to smoke as an adult, but not to the intention to smoke as a teen.

The findings were also inconsistent regarding susceptibility for smoking [21]. In one study, significant findings were found for the association between parental smoking and susceptibility to smoking [40]. When analyses were conducted separately for paternal and maternal smoking patterns, significant effects were found only for paternal smoking [38]. In a majority of studies, it was found that parental smoking was not associated with susceptibility to smoking $[26,29,41,42]$.

Three studies investigated the association between parental smoking and implicit smoking cognitions [23-25]. Two studies found no significant association between parental smoking and adolescent's automatic smoking-related memory associations $[23,25]$. A study by Lochbuehler et al. [24] found an increased attentional focus on smoking-related cues in children with smoking parents, compared to children with non-smoking parents.

\section{Longitudinal Studies}

A total of 8 studies [31, 43-49] employed a longitudinal design to assess the effect of parental smoking on adolescent's smoking-related cognitions. In summary, these studies reported mixed findings. One study [44] reported that parental smoking increased favourable smoking-related beliefs (i.e. less risk perceptions) in children. One study [43] reported that parental smoking decreased favourable smoking-related beliefs (i.e. more negative prototypes of smokers) in children. Five studies $[31,45,46,48,49]$ reported no effect of parental smoking on smoking-related cognitions in children and adolescents (i.e. risk and benefit perceptions, susceptibility to smoking, readiness to quit). Finally, one study [47] reported mixed findings depending on the age of the child. While parental smoking increased favourable smokingrelated cognitions (i.e. more normative perceptions of smoking), but had no effect on intentions to smoke in older siblings, the opposite effect was observed in younger siblings (i.e. parental smoking increased intentions to smoke, but had no effect on normative perceptions). 
None of these studies assessed the effect of parental smoking on adolescent's implicit smoking-related cognitions.

\section{Mediation Studies}

Four longitudinal studies [50-53] examined smokingrelated cognitions as putative mediators in the association between parental and adolescent smoking. The direct effects of parental smoking on smoking-related cognitions are displayed in table 2 . All 4 studies reported a statistically significant indirect effect from parental smoking on youth smoking through at least one putative mediator (indirect effects not displayed). In general, parental smoking increased favourable smoking-related cognitions (i.e. more perceived parental approval of smoking, higher intention to smoke, more positive attitudes towards smoking, higher perceived prevalence of smoking, lower self-efficacy), which in turn increased the likelihood of adolescent smoking. Only in one instance, parental smoking predicted less negative outcome expectations (i.e. perceiving more risks of smoking), which was inversely associated with smoking intentions [50]. Up to now, no study has investigated the role of adolescent's implicit smoking-related cognitions as a putative mediator in the association between parental and adolescent smoking.

\section{Discussion}

The aim of this review was to summarize and discuss the empirical evidence for an association between parental smoking and smoking-related cognitions among youth as well as the evidence for a potential mediating role of smoking-related cognitions in the association between parental and youth smoking. A majority of the 41 included studies had a cross-sectional study design; only 8 studies employed a longitudinal design. Beside this, only 3 studies examined implicit smoking-related cognitions among the youth. Overall, findings across studies showed weak and inconsistent (significant and non-significant) associations between parental smoking and smoking-related cognitions among youth. When examining the results by study design, by type of smoking-related cognition or by taking the study year into account, no distinct pattern in associations could be identified. Results were somewhat more consistent across the mediation studies. Three of the 4 identified studies [50-53] showed that parental smoking increased favourable smoking-related cognitions, which in turn increased the likelihood of adolescent smoking. However, it needs to be emphasized that the number of these mediation studies was quite small. The synthesis of evidence showed that a majority of results reported positive associations between parental smoking and smoking-related cognitions among youth even when non-significant findings were found (table 2). In the following section, we will discuss methodological and theoretical aspects that might explain the mixed pattern of significant and non-significant findings.

\section{Methodological Explanations}

A possible explanation for the inconsistent findings relates to the quality of the studies. A majority of the studies had a cross-sectional study design and only a few studies had the primary aim to investigate the association between parental smoking and adolescent's smoking cognitions. In addition, inconsistencies in findings might be due to differences in assessment instruments. Most studies employed survey instruments with unknown reliability and validity, and some cognition measures might be more sensitive for detecting small changes in cognitions than others. Also, several studies used a different operationalization for the same concept, which makes a comparison of the results difficult. Furthermore, a majority of studies failed to consider the smoking status of the child as a potential covariate and did not distinguish between the different stages in the process of smoking. Therefore, most samples include children and adolescents with a diverse background of smoking behaviour (e.g. never-smoking, initiation, experimentation, occasional smoking, regular smoking, established smoking). It has been shown that smoking status in children and adolescents affects attitudes towards smoking $[54,55]$. Moreover, previous research indicates that young children are generally negative about smoking $[19,56]$ and that the unfavourable smoking-related cognitions in children undergo a developmental shift and reduce when they grow older [54, 57]. Adolescents, compared with children, reported more favourable subjective norms [58], perceived the instrumental benefits of smoking, while retaining a general negative attitude toward smoking [59], and saw smokers in a more positive and non-smokers in a more negative light [60]. Also, in the time from early to middle adolescence, negative consequences of smoking were perceived as more likely than potential benefits $[10,61]$. However, older adolescents perceived the benefits of smoking as more likely and the costs as less likely than younger adolescents $[10,61]$, indicating that the discrepancy between cost and benefits of smoking narrows as children get closer to the risk-age of initiation [10]. Therefore, the results of future research may be more consistent when considering 
the developmental period of youth (child, pre-adolescent, early adolescent, late adolescent) as well as the stage within the process of smoking among youth.

\section{Theoretical Explanations}

A theoretical explanation that may account for the inconsistent findings, relates to the assessment of parental smoking. A majority of studies assessed the current smoking status of parents. However, this does not provide any information about the way that children can be exposed to parental smoking. Exposure to parental smoking consists of different aspects including knowledge of parental smoking, exposure to parental smoking-related cognitions (e.g. attitudes, norms, expectancies), and physiological exposure to second-hand smoke [62]. Smoking-related cognitions in youth may be more strongly related to one of these aspects. Furthermore, the relationship between parental smoking and smoking-related cognitions might be moderated by situational and/or individual characteristics. A relevant factor that might moderate this relationship is smoking-specific parenting or anti-smoking socialization. Previous research has shown that parents who discuss smoking-related issues in a respectful and constructive way can prevent their children from the initiation of smoking [63-67]. Moreover, parental monitoring, rule-setting, and home smoking restrictions have been shown to reduce the risk of smoking initiation [63, 68-71]. Therefore, smoking-specific parenting may moderate the relationship between parental smoking and smoking-related cognitions. The role of smoking-specific parenting has not been examined in a majority of the studies included in this review.

\section{Implications for Theory}

Social learning theories propose that role models shape cognitions and behaviour among youth. The present findings indicate that the formation of smoking-related cognitions cannot be explained entirely by the smoking behaviour of parents. Other sources of environmental smoking (i.e. siblings, peers, media, society as a whole) may also explain the formation of smoking-related cognitions in youth. Moreover, it is possible that the impact of different exposure sources in the social environment varies within different age groups [50,72]. Also, different sources of exposure may communicate different messages regarding smoking, and children may hold positive as well as negative smoking-related cognitions simultaneously. For example, children may observe parental smoking in a positively valued context, which may lead to the formation of positive smoking associations. At the same

Parental Smoking and Youth Smoking Cognitions time, children may perceive a general anti-smoking attitude in society, which may lead to the formation of negative associations with smoking. This indicates that exposure to parental smoking is rather complex and embedded in a broader social environment. Up to now, it is unclear whether exposure to smoking may activate both favourable and unfavourable smoking cognitions in youth and whether different exposure sources may shape different types of cognitions.

Furthermore, it remains unclear how positive and negative smoking-related cognitions relate to the onset of smoking. It may be expected that positive smoking-related cognitions increase the risk of initiation, while negative cognitions prevent the uptake of smoking. The initiation of smoking could depend on whether positive smoking-related cognitions outweigh negative smokingrelated cognitions.

Finally, the interplay between explicit and implicit smoking-related cognitions remains unclear. From a theoretical point of view, it is expected that explicit and implicit smoking-related cognitions underpin different cognitive motivational systems; they should be relatively independent of each other [13, 73, 74]. One empirical study showed that explicit and implicit smoking-related cognitions uniquely predict the onset of smoking [25]. Prospective, longitudinal studies are needed to investigate how explicit and implicit processes develop and interact with each other to influence the initiation of smoking.

\section{Implications for Future Research}

First, the results of this review call for more carefully designed studies in the future. The use of validated instruments, the inclusion of relevant covariates, and the use of prospective study designs and mediation analyses is needed to better understand the mechanisms underlying the transmission of smoking behaviour.

Fundamental research investigating the development of positive and negative explicit and implicit smokingrelated cognitions is needed $[25,75]$. It is important to gain a better understanding of how positive and negative explicit and implicit smoking-related cognitions develop among youth and to determine under which circumstances such cognitions increase the risk of smoking.

A majority of studies did not distinguish between different stages within the process of smoking uptake or the age of the child. Further research on the effect of parental smoking on smoking cognitions during different stages within the process of smoking is needed as the impact of parental smoking on smoking cognitions may fluctuate depending on the age and the smoking status of the child. 
Future research should assess different aspects of parental smoke exposure (e.g. knowledge of parental smoking, exposure to smoking-related attitudes of parents, physiological exposure to second-hand smoke) in order to understand the mechanisms that underlie the effects of parental smoking.

Future research should take other relevant variables into account, which may moderate the relationship between parental smoking and the development of smokingrelated cognitions. As mentioned above, smoking-specific parenting might be a relevant factor. Therefore, future research should investigate whether smoking-specific parenting or other putative moderators can buffer against the effects of parental smoking and prevent children from developing favourable smoking-related cognitions.

\section{Conclusion}

This review examined 41 studies showing inconsistent associations between parental smoking and smoking-related cognitions among youth. The quality of the major- ity of studies as assessed by the NOS [15] was relatively low; the findings suggest that the effects of parental smoking on smoking-related cognitions may be rather modest, and when effects are observed they are usually small. Research has not been able to confirm the commonly applied social learning or cognitive theories in the area of parental smoking and the development of smoking-related cognitions among youth. In order to draw firm conclusions on how parental smoking affects smoking initiation, well-designed studies that examine the mediating role of explicit and implicit smoking cognitions are needed.

\section{Funding}

This study was funded by The Behavioural Science Institute, Radboud University Nijmegen.

\section{Disclosure Statement}

The authors declare that they have no conflict of interest.

\section{References}

1 Leonardi-Bee J, Jere ML, Britton J: Exposure to parental and sibling smoking and the risk of smoking uptake in childhood and adolescence: a systematic review and meta-analysis. Thorax 2011;66:847-855.

2 Avenevoli S, Merikangas KR: Familial influences on adolescent smoking. Addiction 2003;98(suppl 1):1-20.

3 Mayhew KP, Flay BR, Mott JA: Stages in the development of adolescent smoking. Drug Alcohol Depend 2000;59(suppl 1):S61-S81.

4 Bernat DH, Erickson DJ, Widome R, Perry CL, Forster JL: Adolescent smoking trajectories: results from a population-based cohort study. J Adolesc Health 2008;43:334-340.

5 Hu MC, Davies M, Kandel DB: Epidemiology and correlates of daily smoking and nicotine dependence among young adults in the United States. Am J Public Health 2006;96:299-308.

6 Kardia SL, Pomerleau CS, Rozek LS, Marks JL: Association of parental smoking history with nicotine dependence, smoking rate, and psychological cofactors in adult smokers. Addict Behav 2003;28:1447-1452.

7 Lieb R, Schreier A, Pfister H, Wittchen HU: Maternal smoking and smoking in adolescents: a prospective community study of adolescents and their mothers. Eur Addict Res 2003;9:120-130.

8 Ajzen I: The theory of planned behavior. Organ Behav Hum Decis Process 1991;50:179_ 211
9 Bandura A: Social Learning Theory. Oxford, Prentice-Hall, 1977.

10 O'Connor RM, Fite PJ, Nowlin PR, Colder CR: Children's beliefs about substance use: an examination of age differences in implicit and explicit cognitive precursors of substance use initiation. Psychol Addict Behav 2007;21: 525-533.

11 Rooke SE, Hine DW, Thorsteinsson EB: Implicit cognition and substance use: a metaanalysis. Addict Behav 2008;33:1314-1328.

12 Rudman LA: Implicit Measures for Social and Personality Psychology. London, Sage, 2011.

13 Rudman LA, Phelan JE, Heppen JB: Developmental sources of implicit attitudes. Pers Soc Psychol Bull 2007;33:1700-1713.

14 Wiers RW, Bartholow BD, van den Wildenberg E, et al: Automatic and controlled processes and the development of addictive behaviors in adolescents: a review and a model. Pharmacol Biochem Behav 2007;86:263-283.

15 Wells GA, Shea B, O'Connell D, Peterson J, Welch V, Losos M, Tugwell P: The NewcastleOttawa Scale (NOS) for Assessing the Quality of Nonrandomized Studies in Meta-Analyses, 2010.

16 Moher D, Liberati A, Tetzlaff J, Altman DG; PRISMA Group: Preferred reporting items for systematic reviews and meta-analyses: the PRISMA statement. BMJ 2009;339:b2535.

17 Kaplan CP, Nápoles-Springer A, Stewart SL, Pérez-Stable EJ: Smoking acquisition among adolescents and young Latinas: the role of socioenvironmental and personal factors. Addict Behav 2001;26:531-550.

18 Piperakis SM, Garagouni-Araiou F, Argyracouli E, Piperakis AS, Iakovidou-Kritsi Z, Triga A: A survey on smoking habits and attitudes among adolescents in Greece. Int J Adolesc Med Health 2008;20:63-71.

19 Brook U, Mendelberg A, Galili A, Priel I, Bujanover Y: Knowledge and attitudes of children towards cigarette smoking and its damage. Patient Educ Couns 1999;37:49-53.

20 Bandura A: Social Foundations of Thought and Action: A Social Cognitive Theory. Englewood, Prentic-Hall, 1986.

21 Pierce JP, Choi WS, Gilpin EA, Farkas AJ, Merritt RK: Validation of susceptibility as a predictor of which adolescents take up smoking in the United States. Health Psychol 1996; 15:355-361.

22 Hiemstra M, Otten R, van Schayck OC, Engels RCME: Smoking-specific communication and children's smoking onset: an extension of the theory of planned behaviour. Psychol Health 2012;27:1100-1117.

23 Chassin L, Presson C, Rose J, Sherman SJ, Prost $\mathrm{J}$ : Parental smoking cessation and adolescent smoking. J Pediatr Psychol 2002;27:485-496.

24 Lochbuehler K, Otten R, Voogd H, Engels RCME: Parental smoking and children's attention to smoking cues. J Psychopharmacol 2012;26:1010-1016. 
25 Sherman SJ, Chassin L, Presson C, Seo DC, Macy JT: The intergenerational transmission of implicit and explicit attitudes toward smoking. J Exp Soc Psychol 2009;45:313.

26 Thrasher JF, Jackson C, Arillo-Santillán E, Sargent JD: Exposure to smoking imagery in popular films and adolescent smoking in Mexico. Am J Prev Med 2008;35:95-102.

27 Sargent JD, Dalton M: Does parental disapproval of smoking prevent adolescents from becoming established smokers? Pediatrics 2001;108:1256-1262.

28 Kong G, Camenga D, Krishnan-Sarin S: Parental influence on adolescent smoking cessation: is there a gender difference? Addict Behav 2012;37:211-216.

29 Sargent JD, Dalton MA, Beach ML, et al: Viewing tobacco use in movies: does it shape attitudes that mediate adolescent smoking? Am J Prev Med 2002;22:137-145.

30 Thomson CC, Siegel M, Winickoff J, Biener L, Rigotti NA: Household smoking bans and adolescents' perceived prevalence of smoking and social acceptability of smoking. Prev Med 2005;41:349-356.

31 Engels RCME, Van Zundert RM, Kleinjan M: Smoking cessation-specific parenting and parental smoking as precursors of adolescent smoking cognitions and quitting. Addict Behav 2012;37:831-837.

32 van Zundert RM, van de Ven MO, Engels RCME, Otten R, van den Eijnden RJ: The role of smoking-cessation-specific parenting in adolescent smoking-specific cognitions and readiness to quit. J Child Psychol Psychiatry 2007;48:202-209.

33 Schuck K, Otten R, Engels RCME, Kleinjan $\mathrm{M}$ : The role of environmental smoking in smoking-related cognitions and susceptibility to smoking in never-smoking 9-12 year-old children. Addict Behav 2012;37:1400-1405.

34 Weiss JW, Garbanati JA: Relationship of acculturation and family functioning to smoking attitudes and behaviors among AsianAmerican adolescents. J Child Fam Stud 2004 13:193-204.

35 Murphy NT, Price CJ: The influence of selfesteem, parental smoking, and living in a tobacco production region on adolescent smoking behaviors. J Sch Health 1988;58:401-405.

36 Scragg R, Glover M, Paynter J, Wong G, McCool J: Association of parent and best friend smoking with stage of adolescent tobacco smoking. N Z Med J 2010;123:77-87.

37 Mak KK, Ho SY, Day JR: Smoking of parents and best friend - independent and combined effects on adolescent smoking and intention to initiate and quit smoking. Nicotine Tob Res 2012;14:1057-1064.

38 McCool J, Cameron LD, Robinson E: Do parents have any influence over how young people appraise tobacco images in the media? J Adolesc Health 2011;48:170-175.

39 Mahabee-Gittens EM, Huang B, Chen C, Dorn LD, Ammerman RT, Gordon JS: The association of parental self-efficacy and parent-youth connectedness with youth smoking intentions. J Prev Interv Community 2011;39: 194-208.

40 Lim KH, Chong Z, Khoo YY, Kaur J: Parental smoking status, stress, anxiety, and depression are associated with susceptibility to smoking among non-smoking school adolescents in Malaysia. Asia Pac J Public Health 2014;26(5 suppl):81S-90S.

41 Baška T, Warren CW, Hudečková $\mathrm{H}$, et al: The role of family background on cigarette smoking among adolescent school children in Slovakia: findings from the 2007 Slovakia global youth tobacco survey. Int J Public Health 2010;55:591-597.

42 Waa A, Edwards R, Newcombe R, et al: Parental behaviours, but not parental smoking, influence current smoking and smoking susceptibility among 14 and 15 year-old children. Aust N Z J Public Health 2011;35:530-536.

43 Blanton H, Gibbons FX, Gerrard M, Conger KJ, Smith GE: Role of family and peers in the development of prototypes associated with substance use. J Fam Psychol 1997;11:271-288.

44 Chassin L, Presson CC, Todd M, Rose JS, Sherman SJ: Maternal socialization of adolescent smoking: the intergenerational transmission of smoking-related beliefs. Psychol Addict Behav 1998;12:206-216.

45 Forrester K, Biglan A, Severson $\mathrm{HH}$, Smolkowski K: Predictors of smoking onset over two years. Nicotine Tob Res 2007;9: 1259-1267.

46 Morrell HE, Song AV, Halpern-Felsher BL: Predicting adolescent perceptions of the risks and benefits of cigarette smoking: a longitudinal investigation. Health Psychol 2010;29: 610-617.

47 Otten R, Harakeh Z, Vermulst AA, Van den Eijnden RJ, Engels RCME: Frequency and quality of parental communication as antecedents of adolescent smoking cognitions and smoking onset. Psychol Addict Behav 2007; 21:1-12.

48 Polen MR, Curry SJ, Grothaus LC, et al: Depressed mood and smoking experimentation among preteens. Psychol Addict Behav 2004; 18:194-198.

49 Schultz AS, Nowatzki J, Ronson G: Effects of household socialization on youth susceptibility to smoke: differences between youth age groups and trends over time. Am J Public Health 2013;103:e39-e42.

50 Flay BR, Hu FB, Siddiqui O, et al: Differential influence of parental smoking and friends' smoking on adolescent initiation and escalation of smoking. J Health Soc Behav 1994;35: 248-265.

51 Harakeh Z, Scholte RH, Vermulst AA, De Vries H, Engels RCME: Parental factors and adolescents' smoking behavior: an extension of the theory of planned behavior. Prev Med 2004;39:951-961.

52 Otten R, Engels RCME, Prinstein MJ: A prospective study of perception in adolescent smoking. J Adolesc Health 2009;44:478-484.

53 Wyszynski CM, Bricker JB, Comstock BA: Parental smoking cessation and child daily smoking: a 9-year longitudinal study of mediation by child cognitions about smoking. Health Psychol 2011;30:171-176.

54 De Leeuw RN, Engels RCME, Vermulst AA, Scholte RH: Do smoking attitudes predict behaviour? A longitudinal study on the bi-directional relations between adolescents' smoking attitudes and behaviours. Addiction 2008; 103:1713-1721.

55 Stacy AW, Bentler PM, Flay BR: Attitudes and health behavior in diverse populations: drunk driving. Alcohol use, binge eating, marijuana use, and cigarette use. Health Psychol 1994; 13:73-85.

56 Porcellato L, Dugdill L, Springett J: A longitudinal study exploring Liverpool primary schoolchildren's perspectives on smoking. Childhood 2005;12:425-443.

57 Chassin L, Presson CC, Sherman SJ, McGrew $\mathrm{J}$ : The changing smoking environment for middle and high school students: 1980-1983. J Behav Med 1987;10:581-593.

58 Andrews JA, Hampson SE, Barckley M, Gerrard M, Gibbons FX: The effect of early cognitions on cigarette and alcohol use during adolescence. Psychol Addict Behav 2008;22:96106.

59 Freeman D, Brucks M, Wallendorf M: Young children's understandings of cigarette smoking. Addiction 2005;100:1537-1545.

60 Dinh KT, Sarason IG, Peterson AV, Onstad LE: Children's perceptions of smokers and nonsmokers: a longitudinal study. Health Psychol 1995;14:32-40.

61 Chassin L, Presson CC, Rose JS, Sherman SJ: From adolescence to adulthood: age-related changes in beliefs about cigarette smoking in a midwestern community sample. Health Psychol 2001;20:377-386.

62 Kobus K: Peers and adolescent smoking. Addiction 2003;98(suppl 1):37-55.

63 Harakeh Z, Scholte RH, de Vries H, Engels RCME: Parental rules and communication: their association with adolescent smoking. Addiction 2005; 100:862-870.

64 De Leeuw RN, Scholte R, Vermulst A, Engels RCME: The relation between smoking-specific parenting and smoking trajectories of adolescents: how are changes in parenting related to changes in smoking? Psychol Health 2010;25:999-1021.

65 De Leeuw RN, Scholte RH, Sargent JD, Vermulst AA, Engels RCME: Do interactions between personality and social-environmental factors explain smoking development in adolescence? J Fam Psychol 2010;24: 68-77.

66 De Leeuw RN, Scholte RH, Harakeh Z, van Leeuwe JFJ, Engels RCME: Parental Smoking-specific communication, adolescents' smoking behavior and friendship selection. J Youth Adolesc 2008;37:1229-1241.

67 Otten R, Engels RCME, van de Ven MO, Bricker JB: Parental smoking and adolescent smoking stages: the role of parents' current and former smoking, and family structure. J Behav Med 2007;30:143-154. 
68 Emory K, Saquib N, Gilpin EA, Pierce JP: The association between home smoking restrictions and youth smoking behaviour: a review. Tob Control 2010;19:495-506.

69 Chassin L, Presson CC, Rose J, Sherman SJ, Davis MJ, Gonzalez JL: Parenting style and smoking-specific parenting practices as predictors of adolescent smoking onset. J Pediatr Psychol 2005;30:333-344.

70 Jackson C, Dickinson D: Enabling parents who smoke to prevent their children from initiating smoking: results from a 3-year intervention evaluation. Arch Pediatr Adolesc Med 2006;160:56-62.

71 Kodl MM, Mermelstein R: Beyond modeling: parenting practices, parental smoking history, and adolescent cigarette smoking. Addict Behav 2004;29:17-32.
72 Vitaro F, Wanner B, Brendgen M, Gosselin C, Gendreau PL: Differential contribution of parents and friends to smoking trajectories during adolescence. Addict Behav 2004;29: 831-835.

73 Huijding J, de Jong PJ: Automatic associations with the sensory aspects of smoking: positive in habitual smokers but negative in nonsmokers. Addict Behav 2006;31:182-186.

74 Wiers RW, Teachman BA, De Houwer J: Implicit cognitive processes in psychopathology: an introduction. J Behav Ther Exp Psychiatry 2007;38:95-104.

75 Van Der Vorst H, Krank M, Engels RCME, Pieters S, Burk WJ, Mares SH: The mediating role of alcohol-related memory associations on the relation between perceived parental drinking and the onset of adolescents' alcohol use. Addiction 2013;108:526-533.

76 Kurtz ME, Kurtz JC, Johnson SM, Beverly EE: Exposure to environmental tobacco smoke perceptions of African American children and adolescents. Prev Med 1996;25:286-292.
77 Leatherdale ST, Ahmed R: Second-hand smoke exposure in homes and in cars among Canadian youth: current prevalence, beliefs about exposure, and changes between 2004 and 2006. Cancer Causes Control 2009;20:855-865.

78 Loke AY, Wong YP: Smoking among young children in Hong Kong: influence of parental smoking. J Adv Nurs 2010;66:2659-2670.

79 Lorenzo-Blanco EI, Bares C, Delva J: Correlates of Chilean adolescents' negative attitudes toward cigarettes: the role of gender, peer, parental, and environmental factors. Nicotine Tob Res 2012;14:142-152.

80 McCool J, Cameron L, Petrie K, Robinson E: Smoking behaviour and expectations among Auckland adolescents. N Z Med J 2003; 116:U478.

81 Meier KS: Tobacco truths: the impact of role models on children's attitudes toward smoking. Health Educ Q 1991;18:173-182. 